\title{
Fixed point theorems for cyclic weak contractions in partially ordered sets endowed with a complete metric
}

\section{J. HARJANI, F. SABETGHADAM and K. SADARANGANI}

\section{ABSTRACT.}

The purpose of this paper is to present some fixed point results for cyclic weak contractions in partially ordered sets endowed with a complete metric.

Acknowledgements. Research partially supported by“Ministerio de Educacion y Ciencia", Project MTM 2007/65706.

\section{REFERENCES}

[1] Agarwal, R. P., El-Gebeily, M. A. and O'Regan, D., Generalized contractions in partially ordered metric spaces, Appl. Anal., 87 (2008), 109-116

[2] Alber, Ya. I. and Guerre-Delabriere, S., Principles of weakly contractive maps in Hilbert spaces, new results, in Operator Theory, (I. Gohberg, Yu Lyubich, Eds.), Advances and Appl. 98, Birkhauser Verlag, Basel, (1997), $7-22$

[3] Altun, I. and Simsek, H., Some fixed point theorems on ordered metric spaces and applications, Fixed Point Theory Appl., (2010), Article ID 621469

[4] Amini-Harandi, A. and Emami, H., A fixed point theorem for contraction type maps in partially ordered metric spaces and application to ordinary differential equations, Nonlinear Anal., 72 (2010), 2238-2242

[5] Bhaskar, T. G. and Lakshmikantham, V., Fixed point theorems in partially ordered metric spaces and applications, Nonlinear Anal., TMA, 65 (2006), 1379-1393

[6] Harjani, J. and Sadarangani, K., Fixed point theorems for weakly contractive mappings in partially ordered sets, Nonlinear Anal., 71 (2009), 3403-3410

[7] Harjani, J. and Sadarangani, K., Fixed point theorems for mappings satisfying a condition of integral type in partially ordered sets, J. Convex Anal., 17 (2010), 597-609

[8] Karapinar, E., Fixed point theory for cyclic weak $\phi$-contraction, Appl. Math. Lett., 24 (2011), 822-825

[9] Kirk, W. A., Srinivasan, P. S. and Veeramani, P., Fixed points for mappings satisfying cyclical contractive conditions, Fixed Point Theory, 4 (2003), No. 1, 79-89

[10] Lakshmikantham, V. and Ciric, L., Coupled fixed point theorems for nonlinear contractions in partially ordered metric spaces, Nonlinear Anal., 70 (2009), 4341-4349

[11] Nieto, J. J. and Rodriguez-Lopez, R., Contractive mapping theorems in partially ordered sets and applications to ordinary differential equations, Order, 22 (2005), 223-239

[12] Nieto, J. J. and Rodriguez-Lopez, R., Existence and uniqueness of fixed point in partially ordered sets and applications to ordinary differential equations, Acta Math Sinica, Engl., Ser., 23 (2007), 2205-2212

[13] O'Regan, D. and Petrusel, A., Fixed point theorems for generalized contractions in ordered metric spaces, J. Math. Anal. Appl., 341 (2008), 1241-1252

[14] Pacurar, M. and Rus, I. A., Fixed point theory for cyclic $\varphi$-contactions, Nonlinear Anal., 72 (2010), 1181-1187

[15] Petric, M., Some results concerning cyclical contractive mappings, Gen. Math., 18 (2010), No. 4, 213-226

[16] Petric, M., Best proximity point theorems for weak cyclic Kannan contractions, Filomat, 25 (2011), No. 1, 145-154

[17] Ran, A. C. M. and Reurings, M. C. B., A fixed point theorem in partially ordered sets and some applications to matrix equations, Proc. Amer. Math. Soc., 132 (2004), 1435-1443

Received: 09.10.2011; In revised form: 03.02.2012; Accepted: 03.09.2012

2010 Mathematics Subject Classification. 47H10, 54H25.

Key words and phrases. Fixed point, partially ordered sets, complete metric space, cyclic weak contraction.

Corresponding author: K. Sadarangani; ksadaran@dma.ulpgc.es 
[18] Rhoades, B. E., Some theorems on weakly contractive maps, Nonlinear Anal., TMA, 47 (2001), 2683-2693

[19] Rus, I. A., Cyclic representation and fixed points, Ann. Tiberiu Popoviciu Seminar, Funct. Eq., Approx. Convexity, 3 (2005), 171-178

Departamento de MATEMÁTicAS

UNiVERSIDAD DE LAS PALMAS DE GRAN CANARIA

Campus de Tafira Baja, 35017 las Palmas de Gran Canaria, Spain

E-mail address: jharjaniedma.ulpgc.es

E-mail address: ksadaran@dma.ulpgc.es

DEPARTMENT OF MATHEMATiCS

K. N. TOOSI UnIVERSITY OF TECHNOLOGY

P.O. BOX 16315-1618, TEHRAN, IRAN

E-mail address: f. sabetghadamegmail .com 